\title{
Changes in children's food group intake from age 3 to 7 years: comparison of a FFQ with an online food record
}

\author{
Carine Vereecken ${ }^{1,2 *}$, Marc Covents ${ }^{3}$, Inge Huybrechts ${ }^{4}$, Colette Kelly ${ }^{5}$ and Lea Maes ${ }^{2}$ \\ ${ }^{1}$ Research Foundation Flanders, Brussels, Belgium \\ ${ }^{2}$ Department of Public Health, Ghent University, UH Block A, 2nd Floor, De Pintelaan 185, 9000 Ghent, Belgium \\ ${ }^{3}$ Ghent University, Testpracticum, Henri Dunantlaan 2, 9000 Ghent, Belgium \\ ${ }^{4}$ Dietary Exposure Assessment Group, International Agency for Research on Cancer, 150 Cours Albert Thomas, \\ 69372 Lyon CEDEX 08, France \\ ${ }^{5}$ Health Promotion Research Centre, NUI Galway, Galway, Republic of Ireland \\ (Submitted 22 October 2013 - Final revision received 12 February 2014 - Accepted 4 March 2014 - First published online 29 April 2014)
}

\begin{abstract}
Few studies have investigated the relative validity of FFQ in young children and no study has investigated the relative validity of changes in children's food intake in a longitudinal context. The aim of the present study was to compare the FFQ of the longitudinal Family Influences on Food Intake study, assessing children's food intake in the previous 3 months, with a $3 \mathrm{~d}$ online food record when children were 3 and 7 years old, as well as to investigate the relative validity of changes in food group intake over a 4-year period. Parents ( $n$ 89) completed the FFQ and an online food record over three non-consecutive days on two separate occasions (January-April 2008 and 2012). Wilcoxon signed-rank tests and Spearman's correlations were used to compare food group intake and changes in intake assessed using both methods. In 2008, the intake of eleven of the twenty-two food groups was overestimated and that of four food groups underestimated in the FFQ in comparison with the online tool; in 2012, the intake of four food groups was overestimated and that of seven food groups underestimated. Nevertheless, changes in intake did not differ significantly between the two methods for eighteen food groups. Correlations in 2008 and 2012 were, on average, 0.47; correlations between the changes in dietary intake were, on average, 0.26. The results suggest that despite the significant differences between the two methods for a number of food groups at both baseline
\end{abstract} and/or follow-up, the FFQ can be used to monitor changes in dietary intake for groups of young children.

Key words: Relative validity: Children: FFQ: Online recording tools: Evolutions: Changes in intake

Accurate assessment of food intake in children is essential for monitoring dietary habits ${ }^{(1)}$. FFQ are relatively easy and inexpensive to administer and have been used in a large number of epidemiological studies, but less so in those in young children $^{(2)}$. The major limitations of FFQ include the following: the accuracy in estimating intake ${ }^{(3)}$ and capturing dietary details $^{(4)}$ and respondent difficulties in estimating consumption frequencies or answering questions about food groups $^{(2)}$. Moreover, when a new FFQ is developed, when changes are made in FFQ or when FFQ are used with different demographic groups, validation is essential ${ }^{(5)}$.

Few validation studies of FFQ in young children exist and they are limited to a cross-sectional design. In $\mathrm{US}^{(6,7)}$ and Korean $^{(8)}$ studies of preschoolers, the relative validity of FFQ designed to assess nutrient and food group intake, respectively, was measured against that of three and two $24 \mathrm{~h}$ recalls, respectively $\left(n 17^{(6)}, n 233^{(7)}\right.$ and $n 333^{(8)}$ ). In Norway, $7 \mathrm{~d}$ weighed records were used to test the relative validity of nutrient and food intake ${ }^{(9)}$ ( $n$ 187), whereas $3 \mathrm{~d}$ diaries were the standard tools used to assess the relative validity of a beverage questionnaire in assessing beverage, Ca and vitamin D intakes among US children aged 6 months to 5 years ${ }^{(10)}$ ( $n$ 240). Huybrechts et al. investigated the relative validity and reproducibility of a semi-quantitative FFQ to assess food group ${ }^{(11)}$ and $\mathrm{Ca}$ intake $^{(12)}$ against those of a $3 \mathrm{~d}$ diary in Flemish children aged 2.5-6.5 years ( $n$ 650). Vereecken et al. ${ }^{(13)}$ investigated the relative validity of a FFQ against that of a $3 \mathrm{~d}$ online recording tool, Young Children's Nutrition Assessment on the Web (YCNA-W), in a sample of Belgian-Flemish children, participating in the Family Influences on Food Intake (FIFI) study ( $n$ 216).

In longitudinal studies with young children, whose growth and eating habits change rapidly, and in evaluations of interventions to improve diet, it is important to consider the sensitivity of the instruments used to assess changes in dietary intake. Of the

Abbreviations: FIFI, Family Influences on Food Intake; YCNA-W, Young Children's Nutrition Assessment on the Web.

* Corresponding author: C. Vereecken, email carine.vereecken@ugent.be 
few studies that investigated the responsiveness of FFQ to changes in dietary intake over time ${ }^{(14-17)}$, only two examined the responsiveness at a food item level ${ }^{(14,17)}$ and neither focused on children. Collecting data at the food level is important as people eat food, rather than nutrients, and dietary recommendations are communicated in terms of food items and groups ${ }^{(18)}$.

The aim of the present study was to investigate the relative validity of changes in food group intake between 2008 and 2012, from 3 to 7 years of age, assessed with the FIFI-FFQ tool against that of dietary data collected over three nonconsecutive days using an online tool, YCNA-W, in a sample of Belgian-Flemish children. We hypothesised that changes in intake assessed with the FIFI-FFQ would parallel those assessed with YCNA-W. Additionally, agreement between the two methods at separate time points is described.

\section{Methods}

\section{Design and procedure}

To better understand young children's dietary patterns and factors that influence them, a biennial longitudinal study on FIFI was initiated in Flanders (Belgium) in $2008^{(19)}$. A total of eighty schools in East and West Flanders (Belgium), randomly selected from the school list provided by the Ministry of Education, were approached for participation in the study. Among these, forty-six schools and ten subdepartments agreed to participate. Within these schools, parents of children from the first pre-primary grade were invited to participate. The parents were requested to fill in a questionnaire containing a quantitative FFQ, questions on sociodemographic characteristics and questions on several constructs that can influence children's dietary patterns. Data for the longitudinal study were collected from the children's parents at the ages of 3, 5 and 7 years.

In 2008, a subsample of parents, namely all who provided their e-mail address in the questionnaire, were invited via e-mail to fill in the online recording tool YCNA-W for three predefined non-consecutive days over a 2-week period, including one weekend day and two weekdays ${ }^{(20)}$. The parents were instructed to complete the tool in the evening for each particular day. A printable food record sheet was available for the teachers to report details regarding the meals (foods and quantities) of children who ordered their meal at school, which were then recorded online in the evening by the parents. The same procedure was repeated in 2012 for parents who completed both instruments in 2008. Data for the FIFI study were collected between January and April 2008 and follow-up data between January and April 2012. Ethical approval was obtained from the ethical board of Ghent University Hospital. Informed consent was requested from the parents who participated. No incentive was given to the participants.

\section{The Family Influences on Food Intake-FFQ}

To assess children's food intake, the parents were asked to fill in a machine-readable FFQ, with questions on the average consumption of seventy-seven food groups in the previous 3 months. The food items were based on a previously developed $\mathrm{Ca}$ questionnaire ${ }^{(12)}$ for preschoolers, further developed to capture the general dietary habits of young children. The frequency options were as follows: 'never or less than $1 \mathrm{~d}$ per month'; ' $1-3 \mathrm{~d}$ per month'; ' $1 \mathrm{~d}$ per week'; '2 d per week'; '3-4 d per week'; '5-6 d per week'; 'everyday'. The parents were also asked to select the average consumption for each food (group) on the day it was consumed. For each item, three to eight portion sizes were defined, plus an open category (e.g. for milk-based desserts: '67 g (half a jar)', ' $125 \mathrm{~g}$ ( 1 jar)', '250 g ( 2 jars)', etc. and for prepared/cooked vegetables: ' $30 \mathrm{~g}$ ', ' $60 \mathrm{~g}$ ', '90 g', ' 120 g', ' 150 g', ' 180 g', ' 210 g', etc.). In addition, examples of standard measures were given (e.g. 'one small jar $=125 \mathrm{~g}$ ' and one spoon of prepared/cooked vegetables $=30 \mathrm{~g}$ ). From these responses, the average daily intake ( $\mathrm{g}$ or $\mathrm{ml} / \mathrm{d}$ ) of each food item was calculated by multiplying the consumption frequency of each food (group) by the specified portion size. For the few cases where the frequency of consumption was reported and not the portion size, the missing value was replaced with the median reported portion size of consumers in the study. Missing values on the frequency questions were not replaced and for the summation of different food groups were considered as zero values.

The relative validity of the FIFI-FFQ compared with that of a $3 \mathrm{~d}$ online recording tool (YCNA-W) for parental reporting of the intake for 3-year-old children has already been published $^{(13)}$. The results showed a good agreement (Wilcoxon tests revealed no significant difference) for five of the twenty food groups, with lower intakes being reported in the FFQ than in YCNA-W for five food groups and higher intakes in the FFQ than in YCNA-W for ten food groups. Spearman's correlations varied between $0 \cdot 22$ and $0 \cdot 76$.

\section{The online food record: Young Children's Nutrition Assessment on the Web}

Detailed dietary data were collected using the Web-based dietary assessment tool YCNA-W. YCNA-W is based on previously developed and validated tools for adolescents ${ }^{(21,22)}$. Additionally, data collected with the instrument in 2008 in a subsample of the FIFI study were in good agreement with those collected with $3 \mathrm{~d}$ paper-pencil diaries in a second subsample: only for water, a significant higher intake was reported in the diaries ${ }^{(20)}$. A detailed description of YCNA-W has been provided elsewhere ${ }^{(20)}$. In short, the parents logged in with a personal code and were asked to select for each day and each eating occasion the food items consumed from a hierarchically organised menu structure. There were twenty-four eating occasions (for each hour of the day) included in 2008, which were reduced to a more user-friendly version of seven eating occasions in 2012. The menu structure included 800 different food items and pictures of portion sizes for more than 200 food items. More details about the pictures, capturing very small to very large portion sizes, making them useful for very diverse populations, have been reported elsewhere $^{(23)}$. However, the validity of these pictures has been investigated in only adolescents ${ }^{(23)}$. 


\section{Analyses}

Analyses were carried out using SPSS 15.0.1.1 (SPSS, Inc.). Values were considered significant at $P<0 \cdot 05$. Food items were categorised into twenty-two food groups based on nutrient content and food use. Changes in intake between 2008 and 2012 were estimated by subtracting the values recorded in 2008 from those recorded in 2012, so that positive values indicated increases in intake. Descriptives are reported for both methods and time points. Differences in intake and in changes in intake were analysed using Wilcoxon signedrank tests, and correlations were assessed by Spearman's rank correlation coefficients.

\section{Results}

In 2008, 862 of the 1611 parents approached for participation in the FIFI study returned the completed questionnaire. Of the 467 parents who were e-mailed requesting to fill in YCNA-W, 216 completed the FFQ and the food record over $3 \mathrm{~d}$. A total of 160 parents also completed the FFQ in February-March 2012 and were invited to complete YCNA-W. Of the e-mails sent, eighteen could not be delivered; nine parents completed YCNA-W for $1 \mathrm{~d}$, five for $2 \mathrm{~d}$ and ninety-two for $3 \mathrm{~d}$. Only those with $3 \mathrm{~d}$ records were included in additional analyses. From these analyses, three parents were excluded as they reported that their child was sick on one or more days. Girls made up $55 \%$ of the children in the sample ( $n$ 89): the mean age of the children at baseline was 3.4 (SD 0.4), ranging between 2.4 and 4 years. Among the parents, $77 \%$ of the mothers and $58 \%$ of the fathers had a Bachelor's or Master's degree. Those who dropped out of the validation study were less likely to have parents who completed higher education (mothers: 51\%; fathers: $42 \%$ ) and consumed more diet soft drinks and white bread and less brown bread and cheese.

\section{Agreement between the two methods at a} population level

In Table 1, daily food intakes reported in the FFQ and YCNA-W in 2008 and 2012 are compared. Significantly lower intakes were reported in the FFQ than in YCNA-W for four food groups (sugared soft drinks, milk, sugared milk beverages and cheese) at both time points and for three food groups (water, fruit juice and sauces) in 2012. Significantly higher intakes were reported in the FFQ than in YCNA-W for three food groups (white bread, vegetables and milk-based desserts) at both time points, for eight food groups (soup, coffee and tea, breakfast cereals, brown bread, potatoes and grains, meat and meat substitutes, savoury snacks and candy/sweets) in 2008, and for biscuits and pastries in 2012.

\section{Agreement in changes in intake according to both methods}

Changes in intake differed significantly for four food groups between the two methods: the intake of water, potatoes and grain products, and savoury snacks reported in the FFQ increased significantly less when compared with that reported in YCNA-W and a decrease in the intake of milk-based desserts was found in the FFQ only (Table 2). Moreover, for seventeen of the twenty-two food groups, equivalent evolutions were found irrespective of the dietary assessment method used. The intake of nine food groups (water, sugared soft drinks, diet soft drinks, white bread, vegetables, potatoes and grains, meat and meat products, sauces and savoury snacks) increased significantly according to both methods. The intake of two food groups (sugared milk beverages and soya beverages) decreased significantly. For six food groups, no significant changes were found according to both methods. The standard deviations of the differences indicate that, at an individual level, the differences may be large.

\section{Agreement in ranking individuals}

The cross-sectional correlations between the two dietary assessment methods varied substantially from as low as $0 \cdot 11$ to as high as $0 \cdot 74$, with most correlations being significant. On average, the correlations were 0.46 in 2008 and 0.48 in 2012 (Table 3). Correlations between FFQ used at both time points were, on average, 0.45 and those between YCNA-W used at both time points were $0 \cdot 30$. Correlations between the changes in intake according to the FFQ at both time points and according to YCNA-W at both time points were lower, on average, $0 \cdot 26$, with only twelve correlations being significant: coffee and tea; fruit juice; sugared soft drinks; milk; sugared milk beverages; soya beverages; breakfast cereals; white bread; brown bread; vegetables; fruits; meat and meat substitutes.

\section{Discussion}

In the present study, food group intake and changes in intake over time assessed using a FFQ and an online $3 \mathrm{~d}$ recording tool, when the children were 3 and 7 years old, were compared.

First, agreement between the methods at a population level was investigated. In line with the literature ${ }^{(9-11)}$, both overand underestimation of food intake were found when comparing FFQ with other dietary assessment methods. In the study of Huybrechts et $a l .^{(11)}$, the intake of five of the thirteen food groups was overestimated and that of four food groups underestimated, and in the study of Andersen et al. ${ }^{(9)}$, the intake of five of the fifteen items was overestimated and that of five underestimated. In the present study, the intake of more food groups was overestimated in the FFQ than in the YCNA-W at baseline (eleven overestimated $v$. four underestimated), whereas that of more food groups was underestimated at follow-up (four overestimated $v$. seven underestimated). Notably for twelve food groups, significant differences in intake were found between the two methods at just one time point (2008 or 2012). However, none of these significant differences were in the opposite direction for the other time period (i.e. none changed from over- to underestimation or vice versa).

Second, changes in food group intake by method were compared. For seventeen of the twenty-two items, equivalent evolutions (the intake of nine food groups increased, that of two food groups decreased and no change from 2008 to 
Table 1. Dietary intake according to FFQ* and Young Children's Nutrition Assessment on the Web (YCNA-W) $\dagger$ in Belgian-Flemish children ( $n$ 89) (Mean or median values and 25th (P25)-75th (P75) percentiles)

\begin{tabular}{|c|c|c|c|c|c|c|c|c|c|c|c|c|c|c|}
\hline & \multicolumn{3}{|c|}{ FFQ 2008} & \multicolumn{3}{|c|}{ YCNA-W 2008} & \multirow[b]{2}{*}{$P \neq$} & \multicolumn{3}{|c|}{ FFQ 2012} & \multicolumn{3}{|c|}{ YCNA-W 2012} & \multirow[b]{2}{*}{$P \ddagger$} \\
\hline & Mean & Median & P25-P75 & Mean & Median & P25-P75 & & Mean & Median & P25-P75 & Mean & Median & P25-P75 & \\
\hline \multicolumn{15}{|l|}{ Beverages $(\mathrm{ml} / \mathrm{d})$} \\
\hline Water & 276 & 300 & $150-450$ & 265 & 250 & $127-368$ & 0.339 & 374 & 300 & $300-450$ & 426 & 373 & $219-596$ & 0.020 \\
\hline Coffee/tea & 5 & 0 & $0-0$ & 1 & 0 & $0-0$ & 0.006 & 3 & 0 & $0-0$ & 5 & 0 & $0-0$ & 0.774 \\
\hline Fruit juice & 139 & 100 & $29-200$ & 141 & 133 & $13-200$ & 0.496 & 107 & 100 & $29-157$ & 137 & 133 & $0-200$ & 0.044 \\
\hline Sugared soft drinks & 34 & 14 & $0-29$ & 53 & 0 & $0-67$ & 0.029 & 40 & 29 & $14-57$ & 82 & 50 & $0-117$ & $<0.001$ \\
\hline Diet soft drinks & 9 & 0 & $0-2$ & 20 & 0 & $0-0$ & 0.509 & 20 & 0 & $0-21$ & 35 & 0 & $0-0$ & 0.072 \\
\hline Milk & 178 & 125 & $34-252$ & 214 & 167 & $40-343$ & 0.008 & 154 & 125 & $18-250$ & 206 & 150 & $46-310$ & 0.001 \\
\hline Sugared milk beverages & 132 & 86 & $25-200$ & 159 & 133 & $67-256$ & 0.006 & 72 & 29 & $13-100$ & 92 & 67 & $0-150$ & 0.048 \\
\hline Soya beverages & 30 & 0 & $0-0$ & 32 & 0 & $0-0$ & 0.601 & 10 & 0 & $0-0$ & 9 & 0 & $0-0$ & 0.181 \\
\hline \multicolumn{15}{|l|}{ Food $(\mathrm{g} / \mathrm{d})$} \\
\hline Breakfast cereals & 7 & 3 & $0-9$ & 6 & 0 & $0-8$ & 0.018 & 9 & 4 & $2-15$ & 8 & 5 & $0-11$ & 0.159 \\
\hline White bread & 25 & 16 & $9-31$ & 19 & 15 & $0-28$ & 0.011 & 41 & 32 & $18-57$ & 36 & 30 & $0-56$ & 0.018 \\
\hline Brown bread§ & 44 & 47 & $25-61$ & 36 & 30 & $11-59$ & 0.001 & 47 & 46 & $19-61$ & 49 & 44 & $20-78$ & 0.782 \\
\hline Vegetables & 66 & 61 & $36-83$ & 52 & 45 & $22-68$ & $<0.001$ & 77 & 72 & $43-109$ & 69 & 61 & $30-91$ & 0.023 \\
\hline Soup & 73 & 63 & $36-125$ & 61 & 50 & $0-100$ & 0.016 & 83 & 63 & $36-125$ & 73 & 50 & $0-133$ & 0.283 \\
\hline Fruits & 120 & 125 & $71-138$ & 131 & 117 & $69-176$ & 0.470 & 120 & 125 & $72-140$ & 119 & 113 & $50-150$ & 0.389 \\
\hline Potatoes and grains $\|$ & 91 & 86 & $61-112$ & 77 & 73 & $53-98$ & 0.001 & 104 & 100 & $82-114$ & 106 & 98 & $73-125$ & 0.907 \\
\hline Biscuits and pastry & 43 & 40 & $28-54$ & 45 & 38 & $22-59$ & 0.838 & 53 & 46 & $32-64$ & 48 & 40 & $20-69$ & 0.034 \\
\hline Milk-based desserts & 77 & 63 & $36-117$ & 50 & 42 & $0-83$ & $<0.001$ & 61 & 46 & $18-99$ & 53 & 42 & $0-83$ & 0.029 \\
\hline Cheese & 8 & 6 & $2-13$ & 11 & 10 & $2-19$ & 0.024 & 8 & 6 & $2-12$ & 14 & 11 & $0-21$ & 0.001 \\
\hline Meat and meat substitutes & 88 & 87 & $73-107$ & 80 & 77 & $57-101$ & 0.027 & 115 & 113 & $84-143$ & 109 & 108 & $82-128$ & 0.253 \\
\hline Sauces & 17 & 15 & $10-21$ & 21 & 18 & $7-28$ & 0.112 & 23 & 19 & $13-28$ & 33 & 28 & $13-47$ & $<0.001$ \\
\hline Savoury snacks & 5 & 3 & $2-5$ & 2 & 0 & $0-3$ & $<0.001$ & 6 & 4 & $2-7$ & 6 & 0 & $0-13$ & 0.478 \\
\hline Candy and sweets & 32 & 31 & $22-42$ & 25 & 20 & $14-34$ & $<0.001$ & 35 & 32 & $22-45$ & 34 & 30 & $14-47$ & 0.395 \\
\hline
\end{tabular}


Table 2. Comparison of changes in dietary intake between 2008 and 2012 according to FFQ and Young Children's Nutrition Assessment on the Web (YCNA-W)* in Belgian-Flemish children ( $n$ 89) (Mean values and standard deviations; median values and 25th (P25)-75th (P75) percentiles)

\begin{tabular}{|c|c|c|c|c|c|c|c|c|c|c|c|c|c|c|c|}
\hline & \multicolumn{4}{|c|}{ FFQ 2012-2008 } & \multirow[b]{2}{*}{$P 1 \dagger$} & \multicolumn{4}{|c|}{ YCNA-W 2012-2008 } & \multirow[b]{2}{*}{$P 2 \ddagger$} & \multicolumn{4}{|c|}{$\Delta(\Delta \mathrm{YCNA}-\mathrm{W}), \Delta(\mathrm{FFQ})$} & \multirow[b]{2}{*}{$P 3 \S$} \\
\hline & Mean & SD & Median & P25-P75 & & Mean & SD & Median & P25-P75 & & Mean & SD & Median & P25-P75 & \\
\hline \multicolumn{16}{|l|}{ Beverages $(\mathrm{ml} / \mathrm{d})$} \\
\hline Water & 99 & 217 & 0 & $0-150$ & $<0.001$ & 161 & 236 & 140 & $1-307$ & $<0.001$ & 62 & 286 & 47 & $-71-241$ & 0.011 \\
\hline Coffee/tea & -1 & 17 & 0 & $0-0$ & 0.594 & 3 & 15 & 0 & $0-0$ & 0.059 & 5 & 20 & 0 & $0-0$ & 0.053 \\
\hline Fruit juice & -31 & 145 & 0 & $-98-48$ & 0.107 & -4 & 149 & 0 & $-110-96$ & 0.719 & 28 & 165 & -4 & $-66-112$ & 0.342 \\
\hline Sugared soft drinks & 5 & 54 & 7 & $0-29$ & 0.041 & 29 & 109 & 0 & $-22-96$ & 0.010 & 24 & 109 & 0 & $-25-74$ & 0.086 \\
\hline Diet soft drinks & 11 & 29 & 0 & $0-14$ & $<0.001$ & 15 & 77 & 0 & $0-0$ & 0.042 & 4 & 83 & 0 & $-2-0$ & 0.857 \\
\hline Milk & -22 & 144 & 0 & $-78-36$ & 0.330 & -9 & 216 & 0 & $-107-98$ & 0.743 & 13 & 192 & 0 & $-78-117$ & 0.570 \\
\hline Sugared milk beverages & -60 & 130 & -24 & $-100-14$ & $<0.001$ & -67 & 149 & -67 & $-150-8$ & $<0.001$ & -7 & 153 & -7 & $-80-60$ & 0.337 \\
\hline Soya beverages & -20 & 81 & 0 & $0-0$ & 0.010 & -22 & 107 & 0 & $0-0$ & 0.037 & -2 & 50 & 0 & $0-0$ & 0.968 \\
\hline \multicolumn{16}{|l|}{ Food $(g / d)$} \\
\hline Breakfast cereals & 2 & 12 & 0 & $-3-7$ & 0.087 & 2 & 12 & 0 & $-3-8$ & 0.026 & 0 & 15 & 0 & $-5-6$ & 0.998 \\
\hline White bread & 16 & 31 & 15 & $2-30$ & $<0.001$ & 17 & 35 & 13 & $-5-36$ & $<0.001$ & 1 & 32 & -2 & $-20-18$ & 0.872 \\
\hline Brown bread\| & 2 & 36 & 0 & $-24-29$ & 0.728 & 14 & 43 & 10 & $-10-40$ & 0.005 & 11 & 41 & 3 & $-15-28$ & 0.057 \\
\hline Vegetables & 11 & 46 & 11 & $-12-38$ & 0.006 & 17 & 53 & 17 & $-13-46$ & 0.002 & 6 & 58 & 3 & $-23-33$ & 0.504 \\
\hline Soup & 11 & 66 & 0 & $-27-54$ & $0 \cdot 107$ & 12 & 96 & 0 & $-50-75$ & 0.288 & 1 & 109 & 0 & $-61-87$ & 0.813 \\
\hline Fruits & 0 & 67 & -5 & $-29-35$ & 0.930 & -12 & 102 & -13 & $-68-47$ & 0.220 & -12 & 95 & -2 & $-67-50$ & 0.374 \\
\hline Potatoes and grains $q$ & 14 & 40 & 13 & $-7-36$ & 0.002 & 29 & 51 & 29 & $-1-55$ & $<0.001$ & 15 & 58 & 5 & $-21-56$ & 0.039 \\
\hline Biscuits and pastry & 9 & 31 & 6 & $-7-22$ & 0.004 & 3 & 49 & 1 & $-23-25$ & 0.865 & -6 & 51 & -4 & $-30-22$ & 0.163 \\
\hline Milk-based desserts & -17 & 63 & -16 & $-45-11$ & 0.007 & 3 & 57 & 0 & $-33-33$ & 0.708 & 19 & 74 & 12 & $-25-52$ & 0.021 \\
\hline Cheese & -1 & 9 & -1 & $-5-2$ & 0.106 & 2 & 17 & 0 & $-10-11$ & 0.441 & 2 & 17 & 1 & $-8-11$ & 0.225 \\
\hline Meat and meat substitutes & 26 & 42 & 26 & $1-52$ & $<0.001$ & 30 & 47 & 28 & $-1-55$ & $<0.001$ & 4 & 54 & 6 & $-41-45$ & 0.380 \\
\hline Sauces & 6 & 16 & 4 & $-1-11$ & $<0.001$ & 12 & 30 & 7 & $-4-33$ & 0.001 & 6 & 31 & 2 & $-14-23$ & 0.171 \\
\hline Savoury snacks & 1 & 5 & 1 & $0-3$ & $<0.001$ & 4 & 9 & 0 & $0-10$ & $<0.001$ & 3 & 10 & 1 & $-3-9$ & 0.019 \\
\hline Candy and sweets & 3 & 22 & 1 & $-9-14$ & 0.532 & 9 & 25 & 6 & $-4-20$ & 0.001 & 7 & 31 & 6 & $-12-27$ & 0.062 \\
\hline
\end{tabular}

* An online recording tool completed for three non-consecutive days in 2008 and in 2012

† Significance of the Wilcoxon signed-rank test comparing children's food intake data collected with FFQ in 2008 and 2012.

‡ignificance of the Wilcoxon signed-rank test comparing children's food intake data collected with YCNA-W in 2008 and 2012

$\S$ Significance of the Wilcoxon signed-rank test comparing changes in food intake data between 2008 and 2012 according to YCNA-W and FFQ.

All non-refined breads.

Grains: pasta, rice, etc. 
Table 3. Spearman's correlations between dietary intakes assessed with $\mathrm{FFQ}^{*}$ and Young Children's Nutrition Assessment on the Web $($ YCNA-W) $\dagger$ in Belgian-Flemish children ( $n$ 89)

\begin{tabular}{|c|c|c|c|c|c|c|c|c|c|c|}
\hline & \multicolumn{2}{|c|}{$\begin{array}{l}\text { FFQ } 2008 v \text {. } \\
\text { YCNA-W } 2008\end{array}$} & \multicolumn{2}{|c|}{$\begin{array}{l}\text { FFQ } 2012 v \text { v. } \\
\text { YCNA-W } 2012\end{array}$} & \multicolumn{2}{|c|}{$\begin{array}{c}\text { FFQ } 2008 v \text {. } \\
\text { FFQ } 2012\end{array}$} & \multicolumn{2}{|c|}{$\begin{array}{l}\text { YCNA-W } 2008 v \text {. } \\
\text { YCNA-W } 2012\end{array}$} & \multicolumn{2}{|c|}{$\begin{array}{c}\text { YCNA-W } \\
\text { changes } v . F F Q \\
\text { changes }\end{array}$} \\
\hline & $r$ & $P$ & $r$ & $P$ & $r$ & $P$ & $r$ & $P$ & $r$ & $P$ \\
\hline \multicolumn{11}{|l|}{ Beverages $(\mathrm{ml} / \mathrm{d})$} \\
\hline Water & 0.58 & $<0.001$ & 0.56 & $<0.001$ & 0.52 & $<0.001$ & 0.53 & $<0.001$ & 0.20 & 0.054 \\
\hline Coffee/tea & 0.45 & $<0.001$ & 0.28 & 0.008 & 0.50 & $<0.001$ & 0.27 & 0.011 & 0.29 & 0.006 \\
\hline Fruit juice & 0.61 & $<0.001$ & 0.56 & $<0.001$ & 0.33 & 0.002 & 0.44 & $<0.001$ & 0.33 & 0.002 \\
\hline Sugared soft drinks & 0.68 & $<0.001$ & 0.43 & $<0.001$ & 0.51 & $<0.001$ & 0.22 & 0.042 & 0.31 & 0.004 \\
\hline Diet soft drinks & 0.49 & $<0.001$ & 0.65 & $<0.001$ & 0.60 & $<0.001$ & 0.53 & $<0.001$ & 0.20 & 0.063 \\
\hline Milk & 0.57 & $<0.001$ & 0.74 & $<0.001$ & 0.60 & $<0.001$ & 0.50 & $<0.001$ & 0.40 & $<0.001$ \\
\hline Sugared milk beverages & 0.65 & $<0.001$ & 0.60 & $<0.001$ & 0.42 & $<0.001$ & 0.29 & 0.007 & 0.46 & $<0.001$ \\
\hline Soya beverages & 0.67 & $<0.001$ & 0.60 & $<0.001$ & 0.31 & 0.004 & 0.45 & $<0.001$ & 0.49 & $<0.001$ \\
\hline \multicolumn{11}{|l|}{ Food $(g / d)$} \\
\hline Breakfast cereals & 0.59 & $<0.001$ & 0.40 & $<0.001$ & 0.46 & $<0.001$ & 0.23 & 0.030 & 0.24 & 0.024 \\
\hline White bread & 0.38 & $<0.001$ & 0.68 & $<0.001$ & 0.58 & $<0.001$ & 0.30 & 0.004 & 0.46 & $<0.001$ \\
\hline Brown bread $\ddagger$ & 0.58 & $<0.001$ & 0.58 & $<0.001$ & 0.28 & 0.007 & 0.29 & 0.005 & 0.48 & $<0.001$ \\
\hline Vegetables & 0.54 & $<0.001$ & 0.49 & $<0.001$ & 0.43 & $<0.001$ & 0.33 & 0.002 & 0.28 & 0.009 \\
\hline Soup & 0.57 & $<0.001$ & 0.38 & $<0.001$ & 0.50 & $<0.001$ & 0.26 & 0.014 & 0.06 & 0.561 \\
\hline Fruits & 0.44 & $<0.001$ & 0.55 & $<0.001$ & 0.44 & $<0.001$ & 0.26 & 0.014 & 0.37 & $<0.001$ \\
\hline Potatoes and grains§ & 0.45 & $<0.001$ & 0.30 & 0.005 & 0.44 & $<0.001$ & 0.24 & 0.024 & 0.20 & 0.058 \\
\hline Biscuits and pastry & 0.26 & 0.013 & 0.39 & $<0.001$ & 0.46 & $<0.001$ & 0.11 & 0.307 & 0.16 & 0.143 \\
\hline Milk-based desserts & 0.47 & $<0.001$ & 0.59 & $<0.001$ & 0.42 & $<0.001$ & 0.48 & $<0.001$ & 0.21 & 0.057 \\
\hline Cheese & 0.25 & 0.017 & 0.47 & $<0.001$ & 0.42 & $<0.001$ & 0.21 & 0.054 & 0.16 & 0.147 \\
\hline Meat and meat substitutes & 0.12 & 0.280 & 0.44 & $<0.001$ & 0.39 & $<0.001$ & 0.27 & 0.009 & 0.23 & 0.038 \\
\hline Sauces & 0.18 & 0.087 & 0.46 & $<0.001$ & 0.50 & $<0.001$ & 0.03 & 0.788 & 0.12 & 0.257 \\
\hline Savoury snacks & 0.19 & 0.068 & 0.19 & 0.080 & 0.60 & $<0.001$ & 0.12 & 0.253 & 0.10 & 0.373 \\
\hline Candy and sweets & 0.37 & $<0.001$ & 0.37 & $<0.001$ & 0.23 & 0.033 & 0.35 & 0.001 & 0.11 & 0.321 \\
\hline Average & 0.46 & & 0.48 & & 0.45 & & 0.30 & & 0.26 & \\
\hline
\end{tabular}

*FFQ completed by the parents in 2008 and 2012.

†An online recording tool completed by the parents for three non-consecutive days in 2008 and 2012.

$\ddagger$ All non-refined breads.

$\S$ Grains: pasta, rice, etc.

2012 was observed for six food groups) were found irrespective of the dietary assessment method used. The increase in intake is in accordance with the higher energy and nutrient needs of older children ${ }^{(24)}$. The decrease in the intake of sugared milk beverages and soya beverages is in agreement with the lower intakes of milk products in children aged 4-6 years $v$. those aged 3-4 years as described in a study carried out by Huybrechts et al. ${ }^{(24)}$.

Additionally, the evolutions differed significantly for only four items between the two methods (the intake of water, potatoes and grain products, savoury snacks and milk-based desserts). The parallel changes found with the FFQ and YCNA-W and the lack of significant differences in changes in intake at the food group level for most food groups suggest that despite over- and underestimations in 2008 and 2012, the FFQ can be used to monitor changes in intake for most food groups at a population level. However, for water, potatoes and grain products, and savoury snacks, one must consider underestimation of the increase in intake in the FFQ in comparison with YCNA-W, while for milk-based desserts, the decrease in the FFQ may actually be a status quo.

To our knowledge, no other study in the literature has investigated the relative validity of changes in food intake in young children. In a study ${ }^{(14)}$ in adults comparing a FFQ with a diet history over a 6-year period, the authors also reported that changes in mean intake from the diet history interview were mirrored by changes in consumption frequency estimated by the FFQ.

Third, agreement in the ranking of food group intake and changes by method was investigated. The cross-sectional correlations between the two dietary assessment methods varied substantially from as low as $0 \cdot 11$ to as high as $0 \cdot 74$, with most correlations being significant and an average correlation being comparable to those of others ${ }^{(9-11)}$. In the study of Huybrechts et al. ${ }^{(11)}$, Spearman's correlations varied between 0.23 and 0.62 , with, on average, a correlation of 0.42 . In the study of Marshall et $a l^{(10)}$, correlations varied between 0.54 and 0.76 , with an average of 0.66 for 3 -year-olds and of 0.61 for 5-year-olds. In the study of Andersen et al. ${ }^{(9)}$, correlations varied from $0 \cdot 26$ to 0.69 , with an average of $0 \cdot 48$. Given the large day-to-day variation in food group intake ${ }^{(11)}$ and given that a $3 \mathrm{~d}$ record is just a snapshot of a child's usual food intake ${ }^{(25)}$, the correlations are in the range of what could be expected.

Correlations between the changes in dietary intake were lower, on average, $0 \cdot 26$, with only twelve correlations being significant. This is not unexpected as imprecisions in single estimates add up when calculating changes ${ }^{(16)}$. In a study carried out by Osler \& Heitmann ${ }^{(14)}$, the average correlation was $0 \cdot 23$. All but three (of the twenty-four) correlations were significant in their study; however, their sample was much larger ( $n$ 329). A study carried out by Bogers et al. ${ }^{(17)}$, using 
an eighteen-item FFQ and biomarkers, found correlations between changes in plasma carotenoid and vitamin $\mathrm{C}$ concentrations of 0.32 and 0.33 for fruits and of 0.28 and 0.30 for vegetables, respectively.

Finally, some limitations should be noted. The sample was relatively small. There is no gold standard for assessing the validity of usual food intake ${ }^{(5)}$; hence, only relative validation against another dietary assessment instrument that is believed to be more accurate can be established. In the present study, the reference method was the online $3 \mathrm{~d}$ dietary record tool YCNA-W. The software includes 800 food items, and the use of multiple household measures and many food images make it possible to select detailed dietary information in a standardised but nonetheless flexible way. A previous version has been validated in adolescents. Additionally, 2008 data, data of the 3-year-olds, were compared with dietary data collected with paper-pencil diaries in a second subsample ${ }^{(20)}$. However, no real validation of parental reports of children's food intake with a standard reference method in the same sample was done.

The use of an online tool may deter those who are less computer literate $^{(20)}$. Moreover, only participants of the main study, who provided an e-mail address, were contacted to participate in the validation study. These factors plus the demands of dietary record-keeping ${ }^{(26)}$ may have contributed to the nonresponse and dropout rate observed. This might compromise the generalisability of the results, as participants were likely to be highly motivated and may respond differently compared with other populations ${ }^{(27)}$. The healthier eating pattern of the validation sample for a number of food groups and the higher response rate of the more-educated participants were not unexpected and were in agreement with the literature ${ }^{(25,28,29)}$.

YCNA-W was completed for three non-consecutive predefined days, yet the mean of $3 \mathrm{~d}$ is not enough to obtain stable estimates of the habitual diet of children. However, respondent burden ${ }^{(25)}$ precludes increasing the number of days for data collection.

The parent most involved with the child was requested to complete the instruments; however, this cannot be guaranteed. The parents were asked to report their children's food intake for a particular day in the evening. However, it is possible that there was a lapse between recording and the assigned dietary assessment day, which could increase error of types of foods and/or amounts recorded. The parents were asked to report details regarding their children's snacks and lunches consumed at school. As the parents were not present at school, most of this information is likely to be based on what the parents put in the children's lunch boxes and what was left behind, potentially supplemented with information from the children (e.g. when there was a birthday party).

A printable food record sheet was available for the teachers of children who ordered their meal at school. The teachers were asked to report details regarding foods and amounts consumed. However, as in most schools only one or two teachers are present in the school lunchroom, the teachers might not have been able to accurately observe children during the whole lunch period to take into account leftovers or foods swapped.
The parents received the link to the online record after completing the questionnaire; hence, a learning effect by completing food records was avoided; however, the time span did not overlap. Additionally, we cannot exclude that previous experience or the considerable time commitment from participation in the study may have led participants to complete instruments differently with each administration ${ }^{(3)}$. The use of a parental report instrument to test the validity of another parental report instrument is a weakness. Finally, no adjustments were made for multiple testing.

\section{Conclusion}

The findings indicate parallel evolutions in children's food intake at a population level according to both methods, supporting the usefulness of the FFQ to investigate changes in intake over time for groups of children for most food groups. Correlations between the changes in intake were significant for only twelve of the twenty-two food groups and at best weak to moderate $(<0.5)$; however, the short $3 \mathrm{~d}$ reference period might compromise the comparison. Additional studies in a more representative sample are advocated. Moreover, future studies should further investigate whether the cross-sectional differences in average intake between the two methods at different time points hold and how these can be explained.

\section{Acknowledgements}

C. V. is a postdoctoral researcher funded by the Research Foundation Flanders.

The authors' contributions are as follows: C. V. designed the study, collected the data, analysed the data and wrote the manuscript; M. C. assisted with the online data collection; C. K., I. H. and L. M. revised the manuscript.

No competing interests are declared by the authors.

\section{References}

1. Livingstone MB, Robson PJ \& Wallace JM (2004) Issues in dietary intake assessment of children and adolescents. Br J Nutr 92, Suppl. 2, S213-S222.

2. Ziegler P, Briefel R, Clusen N, et al. (2006) Feeding Infants and Toddlers Study (FITS): development of the FITS survey in comparison to other dietary survey methods. $J$ Am Diet Assoc 106, S12-S27.

3. Subar AF, Kipnis V, Troiano RP, et al. (2003) Using intake biomarkers to evaluate the extent of dietary misreporting in a large sample of adults: the OPEN study. Am J Epidemiol 158, $1-13$.

4. Thompson FE \& Subar A (2013) Dietary assessment methodology. In Nutrition in the Prevention and Treatment of Disease, pp. 5-46 [AM Coulston, CJ Boushey and MG Ferruzsi, editors]. London, UK: Elsevier.

5. Cade J, Thompson R, Burley V, et al. (2002) Development, validation and utilisation of food-frequency questionnaires - a review. Public Health Nutr 5, 567-587.

6. Iannotti R, Zuckerman A, Blyer E, et al. (1994) Comparison of dietary intake methods with young children. Psychol Rep 74, 883-889. 
7. Blum RE, Wei EK, Rockett HR, et al. (1999) Validation of a food frequency questionnaire in Native American and Caucasian children 1 to 5 years of age. Matern Child Health J3, 167-172.

8. Kim DW, Oh SY, Kwon SO, et al. (2012) Comparison of validity of food group intake by food frequency questionnaire between pre- and post-adjustment estimates derived from 2-day 24-hour recalls in combination with the probability of consumption. Asian Pac J Cancer Prev 13, 2655-2661.

9. Andersen LF, Lande B, Trygg K, et al. (2004) Validation of a semi-quantitative food-frequency questionnaire used among 2-year-old Norwegian children. Public Health Nutr 7, $757-764$.

10. Marshall TA, Eichenberger Gilmore JM, Broffitt B, et al. (2003) Relative validation of a beverage frequency questionnaire in children ages 6 months through 5 years using 3-day food and beverage diaries. J Am Diet Assoc 103, 714-720.

11. Huybrechts I, De Backer G, De Bacquer D, et al. (2009) Relative validity and reproducibility of a food frequency questionnaire for estimating food intakes among Flemish preschoolers. Int J Environ Res Public Health 6, 382-399.

12. Huybrechts I, De Bacquer D, Matthys C, et al. (2006) Validity and reproducibility of a semi-quantitative food-frequency questionnaire for estimating calcium intake in Belgian preschool children. Br J Nutr 95, 802-816.

13. Vereecken C, Covents M \& Maes L (2010) Comparison of a food frequency questionnaire with an online dietary assessment tool for assessing preschool children's dietary intake. J Hum Nutr Diet 23, 502-510.

14. Osler M \& Heitmann BL (1996) The validity of a short food frequency questionnaire and its ability to measure changes in food intake: a longitudinal study. Int J Epidemiol 25, 1023-1029.

15. Kristal AR, Beresford SA \& Lazovich D (1994) Assessing change in diet-intervention research. Am J Clin Nutr 59, 185S-189S

16. Pijls LT, de Vries H, Donker AJ, et al. (1999) Reproducibility and biomarker-based validity and responsiveness of a food frequency questionnaire to estimate protein intake. $\mathrm{Am} \mathrm{J}$ Epidemiol 150, 987-995.

17. Bogers RP, van Assema P, Kester AD, et al. (2004) Reproducibility, validity, and responsiveness to change of a short questionnaire for measuring fruit and vegetable intake. $A m$ J Epidemiol 159, 900-909.
18. Millen AE, Midthune D, Thompson FE, et al. (2006) The National Cancer Institute Diet History Questionnaire: validation of pyramid food servings. Am J Epidemiol 163, 279-288.

19. Vereecken CA (2010) [A longitudinal study on dietary habits and the primary socialization of these habits in young children]. Verh K Acad Geneeskd Belg 72, 295-308.

20. Vereecken C, Covents M, Haynie D, et al. (2009) Feasibility of the Young Children's Nutrition Assessment on the Web. J Am Diet Assoc 109, 1896-1902.

21. Vereecken CA, Covents M, Matthys C, et al. (2005) Young adolescents' nutrition assessment on computer (YANA-C). Eur J Clin Nutr 59, 658-667.

22. Vereecken C, Covents M, Sichert-Hellert W, et al. (2008) Development and evaluation of a self-administered computerized 24-hour dietary recall method for adolescents in Europe. Int J Obes (Lond) 32, 26-34.

23. Vereecken C, Dohogne S, Covents M, et al. (2010) How accurate are adolescents in portion-size estimation using the computer tool Young Adolescents' Nutrition Assessment on Computer (YANA-C)? Br J Nutr 103, 1844-1850.

24. Huybrechts I, Matthys C, Vereecken C, et al. (2008) Food intakes by pre-school children in Flanders compared with recommendations. Int J Environ Res Public Health 5, 243-257.

25. Vereecken C, Covents M, Maes L, et al. (2014) Formative evaluation of the dietary assessment component of Children's and Adolescents' Nutrition Assessment and Advice on the Web (CANAA-W). J Hum Nutr Diet 27, Suppl. 1, 54-65.

26. Berg C, Jonsson I, Conner MT, et al. (1998) Sources of bias in a dietary survey of children. Eur J Clin Nutr 52, 663-667.

27. Riboli E, Toniolo P, Kaaks R, et al. (1997) Reproducibility of a food frequency questionnaire used in the New York University Women's Health Study: effect of self-selection by study subjects. Eur J Clin Nutr 51, 437-442.

28. Oenema A, Brug J \& Lechner L (2001) Web-based tailored nutrition education: results of a randomized controlled trial. Health Educ Res 16, 647-660.

29. Papadaki A \& Scott JA (2006) Process evaluation of an innovative healthy eating website promoting the Mediterranean diet. Health Educ Res 21, 206-218. 